\title{
PERFORATION OF THE INTERVENTRICULAR SEPTUM DUE TO CARDIAC INFARCTION
}

\author{
BY \\ ANNE M. WOOD \\ From the Harrogate General Hospital \\ Received August 10, 1944
}

Until December 1943 thirty-eight cases of rupture of the interventricular septum have been reported; of these eight were diagnosed ante-mortem. Rupture of the septum usually occurs in the seventh and eighth decades in patients who have had long-standing high blood pressure. It is more common in first infarctions, where the infarct is small and the blood pressure remains above $160 / 100$ after infarction. The average time of rupture is between the third and twelfth days (Edmunson and Hoxie, 1942).

Stanley (1937) reported that, at the time of rupture of the septum, his patient complained of sudden substernal pain and became shocked. After rupture a systolic murmur, which may be rough or blowing, has been noticed over the sternum in the fourth and fifth interspaces in all reported cases, generally accompanied by a systolic thrill (Sagar, 1934). In all cases observed within two or three hours of rupture there has been cyanosis and dyspnoa and usually there has been some degree of congestive failure throughout the illness; death usually being due to right ventricle failure (Bayley and Fader, 1941).

Although most reported cases have died during the first week after perforation of the septum, diminution of the congestive failure has followed prolonged use of mercurial diuretics (Wood and Livezey, 1942) and digitalis therapy (Leonard and Daniels, 1938).

Seven cases have been reported that lived for more than four weeks, of which Moulton (1942) mentions four. The longest recorded duration of life after perforation is four years and ten months (Wood and Livezey, 1942). Gross and Schwartz (1936) record a case which survived two months and Stanley (1937) ŏne which lived five months.

\section{CASE REPORT}

E. M. V., a woman aged 69 years, was admitted to hospital on 27/10/43. She had been known to have high blood pressure for the preceding year. For fourteen months before admission she had complained of aching across the shoulders and down both arms, occurring on exertion and immediately relieved by rest. On 17/10/43, ten days before admission, she had an acute attack of pain in the shoulders and down both arms, which came on at rest. The pain lasted about an hour, and was followed by a feeling of faintness. After the attack she became increasingly dyspnœic on exertion, but there was no recurrence of the pain.

On admission to hospital she was not cyanosed and there was no dyspnœa at rest. The pulse was regular at a rate of 120 . The blood pressure was 100/70. The apex beat was four and a half inches to the left in the fifth interspace and was diffuse and moderately beaving. A thrill was not felt. A blowing systolic murmur was heard over the lower sternum, replacing both sounds in this area; it was conducted towards the axilla and up the sternum. There was slight odema over the sacrum. The veins of the neck were not distended and the liver was not palpable. Crepitations were heard at both pulmonary bases.

A cardiogram (Fig. 1) showed evidence of recent posterior infarction. A radiogram showed cardiac enlargement to the right and left, and basal pulmonary congestion. The white count was 15,000 , of which 68 per cent were polymorphonuclear. The blood urea was $55 \mathrm{mg}$. per 100 c.c. of blood. Urine analysis showed a trace of albumin, an occasional erythrocyte, and a few leucocytes. The blood sedimentation rate was 14 (Wintrobe).

She was treated with ammon. chlor., grains 30 , and with neptal, 2 c.c. intramuscularly every third day, which produced a moderate diuresis, and later with cardophylin intravenously and by mouth, to which she showed no response. 

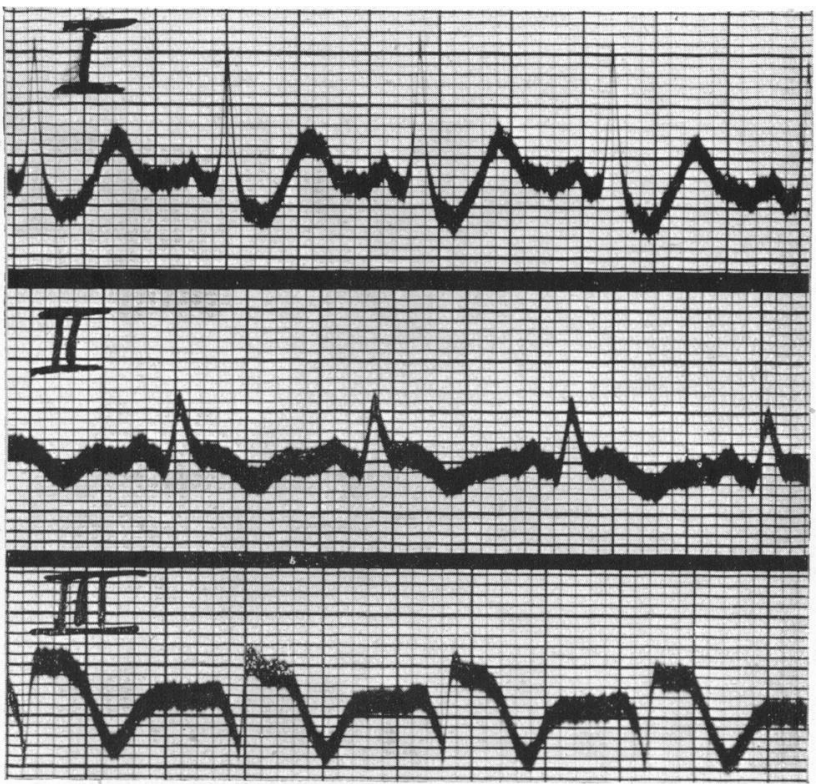

Fig. 1.-Electrocardiogram with evidence of posterior infarction-depression of the S-T junction in lead I, and bowed inversion of $\mathbf{T}$ in leads II and III.

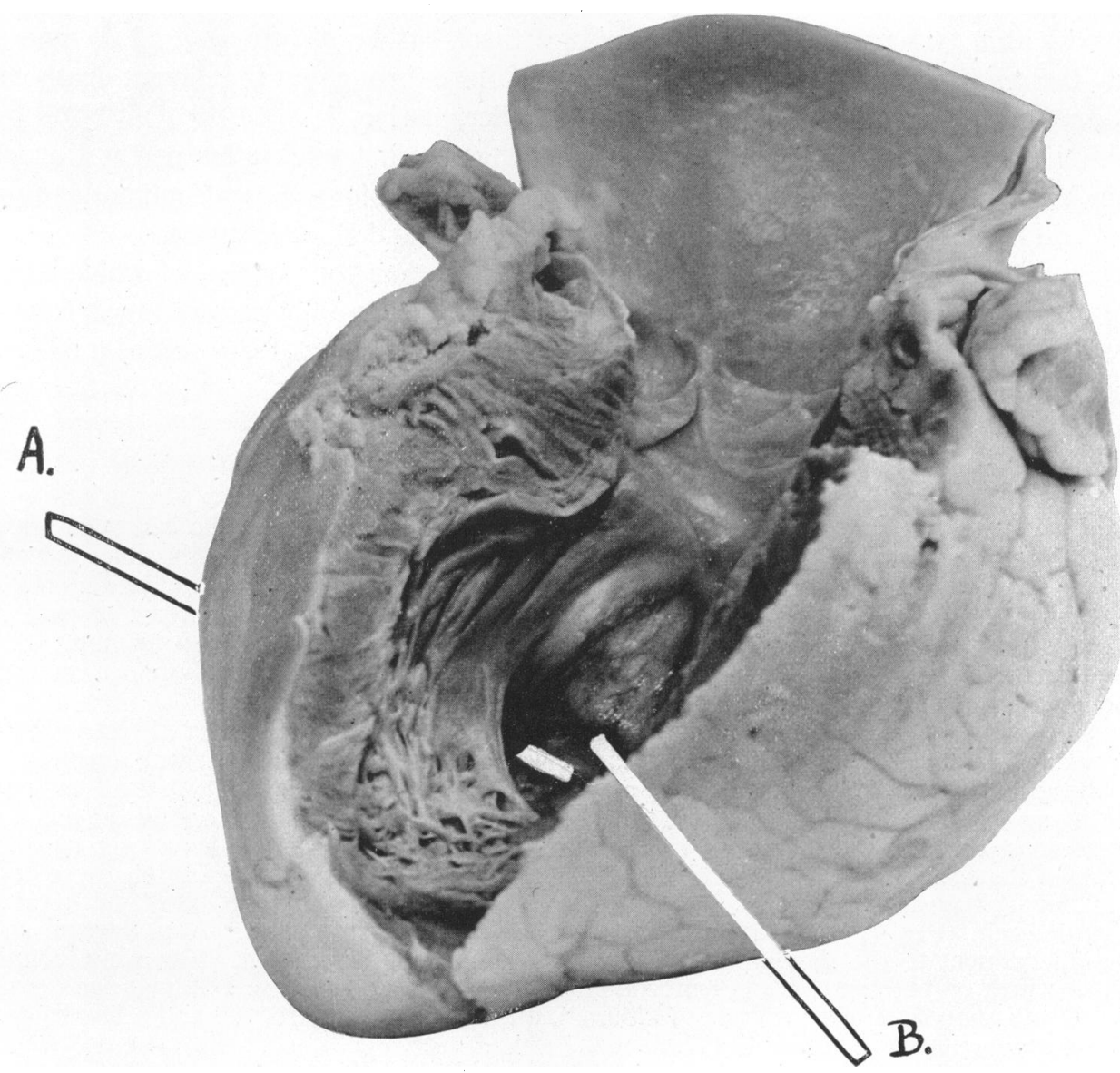

FIG. 2.-Photograph of heart showing perforation of interventricular septum. (A) Perforation in the interventricular septum. (B) Aneurysmal dilatation seen from the left ventricle. 
The heart sounds remained constant and there was no noticeable increase in the heart size. A cardiogram taken after four weeks continued to show signs of infarction but no other abnormality. The pulse rate was persistently rather rapid, varying between 88 and 124. Crepitations persisted at the pulmonary bases throughout her illness but the sacral œdema rapidly disappeared. There was no further development of congestive failure, though the patient frequently complained of nausea and vomited occasionally.

The patient lived for five weeks after admission to hospital, during which time her general condition improved slowly until two hours before death, when she complained of gradually increasing præcordial pain with nausea and faintness. She became collapsed and her blood pressure fell. This was considered to be due to further cardiac infarction.

Post-mortem findings. (Dr. S. Wray). The heart weighed approximately $400 \mathrm{~g}$. and showed slight general enlargement. The thickness of the left ventricle was $18 \mathrm{~mm}$. (normal 6-12 mm.), and of the right, $9 \mathrm{~mm}$. (normal $3 \cdot 2 \mathrm{~mm}$.).

The lumen of the right coronary artery was almost obliterated by old thrombus but was just patent. The posterior part of the left ventricle and the posterior part of the interventricular septum showed ischæmic changes due to an infarction of some weeks duration. In the posterior part of the septum, including the membranous septum, there was an aneurysmal dilatation extending into the right ventricle. The base was $30 \times 20 \mathrm{~mm}$. in area, and it was $15 \mathrm{~mm}$. deep. At its apex there was a slit-like perforation, $10 \mathrm{~mm}$. long, giving free communication between the ventricles. The walls of the aneurysmal sac, and of the perforation, at its apex, were smooth, suggesting that the lesion was of some weeks duration. There was nothing to suggest that the lesion was of congenital origin. (Fig. 2). The part of the endocardium of the right ventricle immediately opposite the perforation showed a thickened area, whiter than the surrounding tissue.

The descending branch of the left coronary artery was completely occluded in its upper part by an atheromatous plaque and super-added recent thrombosis. The myocardium of the anterior part of the left ventricle showed very recent infarction.

The valves of the heart were normal. The right pleural cavity contained about half a pint of clear yellow fluid. The lungs showed basal œdema only. The liver was normal in size, but of mild nutmeg appearance.

\section{Discussion}

Before death the diagnosis made with some confidence was a rupture of the interventricular septum following posterior cardiac infarction. The diagnosis was based on the recent development of a systolic murmur beneath the sternum, following a single cardiac infarction, in a patient who was known to have had high blood pressure.

The signs were not typical of the condition as it has been previously described, as there was no history of any initial shock, no systolic thrill, and the systolic murmur was blowing rather than rough. These atypical findings may be due to the fact that the infarcted septal area was first stretched to form an aneurysmal dilatation, and only later became sufficiently thin to perforate. In this case the perforation might occur slowly, so that there would be no initial shock. The absence of thrill might be due to a slow rate of blood flow through the perforation because of the presence of the aneurysm. Compensation for the abnormal circulation was established by the relative hypertrophy of the right ventricle. This explains the absence of marked congestive failure.

The effects of perforation of the interventricular septum in this case were a rapid pulse rate and persistent basal pulmonary œdema.

\section{SUMMARY}

A case of rupture of the interventricular septum, accompanied by an aneurysmal dilatation of the septum is described. The signs were not typical. An explanation of the atypical findings is attempted.

I wish to thank Dr. C. W. Curtis Bain for his interest and help.

\section{REFERENCES}

Bayley, R. H. and Fader, D. E. (1941). Amer. Heart J., 21, 238.

Edmunson, H. N. and Hoxie, H. J. (1942). Ibid., 24, 719.

Gross, H. and Schwartz, S. P. (1936). Ibid., 11, 626.

Moulten, S. E. (1942). Arch. intern. Med., 69, 108.

Sager, R. V. (1934). Ibid., 53, 140.

Stanley, D. F. (1937). Amer. Heart J., 14, 420.

Wood, F. C. and Livezey, M. M. (1942). Ibid., 24, 807. 